\title{
Food restriction induces in vivo ventricular dysfunction in spontaneously hypertensive rats without impairment of in vitro myocardial contractility
}

K. Okoshi' ${ }^{1}$, J.R. Fioretto ${ }^{2}$, M.P. O koshi ${ }^{1}$, A.C. Cicogna ${ }^{1}$, F.F. Aragon ${ }^{1}$, L.S. Matsubara ${ }^{1}$ and B.B. Matsubara ${ }^{1}$

\author{
Departamentos de ${ }^{1}$ Clínica Médica and ${ }^{2}$ Pediatria, \\ Faculdade de Medicina de Botucatu, \\ Universidade Estadual Paulista, Botucatu, SP, Brasil
}

\section{Correspondence \\ J.R. Fioretto \\ Departamento de Pediatria \\ Faculdade de Medicina, UNESP \\ Caixa Postal 530 \\ 18618-970 Botucatu, SP \\ Brasil \\ Fax: +55-14-6822-0421 \\ E-mail: jrf@ fmb.unesp.br}

Research supported by FAPESP (No. 95/4318-5).

Received May 8, 2003

Accepted January 22, 2004

\section{Abstract}

Cardiac structures, function, and myocardial contractility are affected by food restriction (FR). There are few experiments associating undernutrition with hypertension. The aim of the present study was to analyze the effects of FR on the cardiac response to hypertension in a genetic model of hypertension, the spontaneously hypertensive rat (SHR). Five-month-old SHR were fed a control or a calorie-restricted diet for 90 days. Global left ventricle (LV) systolic function was evaluated in vivo by transthoracic echocardiogram and myocardial contractility and diastolic function were assessed in vitro in an isovolumetrically beating isolated heart (Langendorff preparation). FR reduced $\mathrm{LV}$ systolic function (control (mean $\pm \mathrm{SD}$ ): $58.9 \pm 8.2 ; \mathrm{FR}$ : $50.8 \pm 4.8 \%, \mathrm{~N}=14, \mathrm{P}<0.05$ ). Myocardial contractility was preserved when assessed by the $+\mathrm{dP} / \mathrm{dt}$ (control: $3493 \pm 379$; FR: $3555 \pm 211$ $\mathrm{mmHg} / \mathrm{s}, \mathrm{P}>0.05$ ), and developed pressure (in vitro) at diastolic pressure of zero (control: $152 \pm 16$; FR: $149 \pm 15 \mathrm{mmHg}, \mathrm{N}=9$, P > 0.05 ) and $25 \mathrm{mmHg}$ (control: $155 \pm 9$; FR: $150 \pm 10 \mathrm{mmHg}, \mathrm{N}=9, \mathrm{P}$ $>0.05)$. FR also induced eccentric ventricular remodeling, and reduced myocardial elasticity (control: $10.9 \pm 1.6$; FR: $9.2 \pm 0.9 \%, \mathrm{~N}=$ 9, $\mathrm{P}<0.05$ ) and LV compliance (control: $82.6 \pm 16.5$; FR: $68.2 \pm 9.1 \%$, $\mathrm{N}=9, \mathrm{P}<0.05)$. We conclude that FR causes systolic ventricular dysfunction without in vitro change in myocardial contractility and diastolic dysfunction probably due to a reduction in myocardial elasticity.

\section{Introduction}

Researchers have long believed that the heart is spared in the presence of undernutrition and have focused their studies on other organs and systems that are strongly affected
Key words

- Undernutrition

- Isolated heart

- Echocardiogram

- Langendorff preparation

- Ventricular remodeling by food restriction (FR).

Today it has been well established that the heart can be challenged by FR. Many clinical and experimental studies have shown that cardiac structure, function, and myocardial contractility are affected during FR (1- 
6), with important ultrastructural changes occurring in the rat myocardium $(4,6)$. We have previously demonstrated that FR increases myocardial hydroxyproline concentration and causes left ventricular (LV) eccentric remodeling and diastolic dysfunction (7). We have also observed that FR induces major ultrastructural changes in the myocardium of normotensive and spontaneously hypertensive rats (SHR) $(4,8)$. If these pathological conditions, hypertension and undernutrition, coexist in the same individual, we may assume that ventricular function is markedly affected. However, there are few experiments associating undernutrition with systemic arterial hypertension $(4,9,10)$. This association is very interesting because undernutrition is a low nutrient supply condition, while systemic arterial hypertension causes further energy consumption by increasing myocardial protein synthesis (11).

The aim of the present study was to analyze the effects of FR on in vivo LV systolic function and on in vitro LV contractility and diastolic function in a genetic model of hypertension, the SHR. To the best of our knowledge, this is the first study of SHR with FR in which the echocardiogram and isolated heart technique are used in the same animal.

\section{Material and Methods}

\section{Study groups}

All investigations were performed according to the Guide for the Care and Use of Laboratory Animals published by the U.S. National Institutes of Health and were approved by the Animal Research Committee of the Medical School of Botucatu, São Paulo, Brazil.

Five-month-old male SHR were fed a control or a restricted diet for 90 days. The control group $(\mathrm{N}=23)$ had free access to regular rat chow (Purina Labina ${ }^{\circledR}$, São Paulo, SP, Brazil), and its consumption was meas- ured daily. The animals subjected to FR $(\mathrm{N}=$ 23) received $50 \%$ of the amount of chow consumed by the control group on the previous day. Water was provided ad libitum. The rats were housed in individual cages at room temperature $\left(23^{\circ} \mathrm{C}\right)$ on a 12 -h light/dark cycle. Body weight was measured once a week and blood pressure was recorded at the beginning of the protocol and before sacrifice using the indirect tail-cuff technique (12).

\section{Echocardiographic study}

At the end of the 90-day FR experimental protocol an echocardiogram was obtained for 14 animals from each group to evaluate heart structure and function using a commercially available SONOS 2000 echocardiographic machine (Hewlett-Packard Medical Systems, Andover, MA, USA) equipped with a 7.5-MHz phased array transducer. Imaging was performed with a $60^{\circ}$ sector angle and 3cm imaging depth. Rats were anesthetized by intramuscular injection of a mixture of ketamine $(50 \mathrm{mg} / \mathrm{kg})$ and xylazine $(1 \mathrm{mg} /$ $\mathrm{kg}$ ), their chest was shaved and the animals were placed in left lateral decubitus. Twodimensionally targeted M-mode echocardiograms were obtained from short-axis views of the LV at or just below the tip of the mitral valve leaflets, and recorded on a black-andwhite thermal printer (SONY UP-890MD) at a sweep speed of $100 \mathrm{~mm} / \mathrm{s}$. All LV tracings were measured manually with a caliper by the same observer, and according to the leading-edge method of the American Society of Echocardiography (13). Data are reported as the mean of at least five consecutive cardiac cycles. LV end-diastolic diameter (LVDD) and LV wall thickness (LVWT) were measured at maximum diastolic diameter, and the LV end-systolic diameter (LVSD) was measured at maximum anterior motion of the posterior wall. The LVWT/ LVDD ratio was used to assess geometric variation of the chamber. LV systolic function was assessed by calculating the frac- 
tional shortening index ((LVDD-LVSD)/ LVDD x 100).

Intra-observer (K.O.) variability was calculated by reading the $\mathrm{M}$-mode tracings twice in a blind fashion (mean \pm SD; LVDD: 1.31 \pm 1.55 ; LVSD: $2.49 \pm 1.91$; LVWT: $2.60 \pm$ $1.56 \%)$.

\section{Left ventricular study - Langendorff preparation}

The in vitro study was performed on 9 animals from each group after the echocardiogram. Hearts from four animals were frozen and stored for later morphological study. One heart was eliminated from the in vitro study because it did not reach stability. The hearts were studied using a modified Langendorff preparation procedure as previously described (7). Briefly, rats were anesthetized with sodium thiopental $(50 \mathrm{mg} / \mathrm{kg}$, ip) and heparinized (1,000 IU). The chest was entered by median sternotomy under artificial ventilation. The ascending aorta was isolated and cannulated for retrograde perfusion with filtered oxygenated Krebs-Henseleit solution maintained at constant temperature and perfusion pressure, $37^{\circ} \mathrm{C}$ and $75 \mathrm{mmHg}$, respectively. The Krebs-Henseleit solution, gassed with $95 \%$ oxygen-5\% carbon dioxide, $\mathrm{pH}$ 7.3-7.4, had the following composition: $115 \mathrm{mM} \mathrm{NaCl}, 5.4 \mathrm{mM} \mathrm{KCl}, 1.2 \mathrm{mM}$ $\mathrm{MgSO}_{4}, 2.5 \mathrm{mM} \mathrm{CaCl}_{2}, 1.15 \mathrm{mM} \mathrm{NaH}_{2} \mathrm{PO}_{4}$, $25 \mathrm{mM} \mathrm{NaHCO}_{3}, 11 \mathrm{mM}$ glucose, and $8 \mathrm{mM}$ mannitol. The heart was removed quickly from the chest and attached to the perfusion apparatus (model 830; Hugo Sachs Elektronic, Grunstasse, Germany). The pulmonary artery was cut to vent the right ventricle during systole, the left atrial appendage was removed, and a latex balloon $(7 \mathrm{~mm}$ in length) was placed inside the LV via the mitral valve orifice. The balloon was already attached to a plastic cannula connected to a three-way stopcock through which the balloon was filled with saline solution or emptied; ventricular pressure was measured us- ing a P23XL transducer and a polygraph (model 40-9800-20 Windograph; Gould, Valleyview, OH, USA). Once the heart developed stable isovolumetric contractions (maintenance of systolic and diastolic pressure at a certain intraventricular volume), the balloon volume was increased in $20-\mu 1$ increments over an end-diastolic pressure range of 0-25 $\mathrm{mmHg}$. Pressure and volume within the balloon were recorded after each increase and corresponded to the LV pressure and volume, respectively. The volume at zero end-diastolic pressure reflects unstressed ventricular volume (V0), which was used as an index of chamber size. To ensure stability of the preparation, two or three data sets were recorded. All hearts were paced from the right atrium at 230 beats/min using an artificial pacer (model 79232; Hugo Sachs Elektronic).

Diastolic function was analyzed by measuring or calculating the following variables: maximal rate of decrease in $\mathrm{LV}$ pressure (-dP/dt, index of myocardial relaxation), percent variation in LV volume required to increase diastolic pressure from 0 to 25 $\mathrm{mmHg}\left(\Delta \mathrm{V}_{25}\right.$, index of $\mathrm{LV}$ compliance), and percent myocardial strain caused by a diastolic stress of $25 \mathrm{~g} / \mathrm{cm}^{2}$ ( $\varepsilon_{25}$, index of myocardial elasticity). Myocardial elasticity was calculated as follows $(14,15)$ :

stress $=\left(1.36 \times\right.$ LVP $\left.\times V^{2 / 3}\right) /[(V+0.943 \times$ $\left.\mathrm{LVW})^{2 / 3}-\mathrm{V}^{2 / 3}\right]$

strain $=\left\{\left[\mathrm{V}^{1 / 3}+(\mathrm{V}+0.943 \times \mathrm{LVW})^{1 / 3}\right] /\right.$ $\left.\left[\mathrm{V} 0^{1 / 3}+(\mathrm{V} 0+0.943 \times \mathrm{LVW})^{1 / 3}\right]-1\right\} \times 100$

where LVP is LV pressure $(\mathrm{mmHg}), \mathrm{V}$ is chamber volume (ml), LVW is left ventricular weight $(\mathrm{g})$, and $\mathrm{V} 0$ is volume $(\mathrm{ml})$ at a diastolic pressure of $0 \mathrm{mmHg}$.

Contractile function was assessed on the basis of the following variables: maximal rate of rise in LV pressure $(+\mathrm{dP} / \mathrm{dt})$; developed pressures at diastolic pressures of 0 and $25 \mathrm{mmHg}$ ( $\mathrm{P}_{\text {iso }} 0$ and $\mathrm{P}_{\text {iso }} 25$, respectively); and developed stress at diastolic pressures of 
0 and $25 \mathrm{mmHg}$ (DS-0 and DS-25, respectively). Developed stress was calculated using the same formula as described above.

\section{Statistical analysis}

Data are reported as means $\pm \mathrm{SD}$. Differences between groups were determined by the unpaired two-tailed Student $t$-test, with the level of significance set at $\mathrm{P}<0.05$.

Table 1. General characteristics of rats and echocardiographic data.

\begin{tabular}{lll}
\hline & Control & Food restriction \\
\hline BWi (g) & $350 \pm 20$ & $345 \pm 14$ \\
BW (g) & $380 \pm 33$ & $258 \pm 22^{*}$ \\
HR (in vivo, bpm) & $268 \pm 43$ & $240 \pm 24$ \\
SBP (mmHg) & $190 \pm 24$ & $196 \pm 21$ \\
LVDD (mm) & $7.03 \pm 0.46$ & $6.96 \pm 0.45$ \\
LVSD (mm) & $2.91 \pm 0.70$ & $3.44 \pm 0.47^{*}$ \\
LVWT (mm) & $1.97 \pm 0.14$ & $1.64 \pm 0.17^{*}$ \\
LVDD/BW (mm/kg) & $18.7 \pm 1.2$ & $27.2 \pm 3.2^{*}$ \\
FS (\%) & $58.9 \pm 8.2$ & $50.8 \pm 4.8^{*}$
\end{tabular}

Data are reported as means \pm SD for 14 animals in each group. BWi = body weight at the beginning of the food restriction (FR) protocol; $\mathrm{BW}=$ body weight at the end of the FR protocol; $H R=$ heart rate; SBP = tail-cuff systolic blood pressure; LVDD = left ventricular diastolic diameter; LVSD $=$ left ventricular systolic diameter; LVWT = left ventricular wall thickness; FS = left ventricular fractional shortening.

$* \mathrm{P}<0.05$ vs control (Student t-test).

Table 2. Structural study of the left ventricle in an isolated Langendorff heart preparation.

\begin{tabular}{lcc}
\hline & Control & Food restriction \\
\hline LWW $(\mathrm{g})$ & $1.11 \pm 0.11$ & $0.73 \pm 0.07^{*}$ \\
VO $(\mathrm{ml})$ & $0.25 \pm 0.04$ & $0.23 \pm 0.03$ \\
LWW/BW $(\mathrm{g} / \mathrm{kg})$ & $2.98 \pm 0.13$ & $2.98 \pm 0.28$ \\
Vo/BW $(\mathrm{ml} / \mathrm{kg})$ & $0.67 \pm 0.10$ & $0.96 \pm 0.17^{*}$
\end{tabular}

Data are reported as means \pm SD for 9 animals in each group. LWW = left ventricular weight; V0 = left ventricular unstressed volume; BW = body weight.

$* \mathrm{P}<0.05$ vs control (Student t-test).

\section{Results}

There were no differences in initial body weight (BWi) between the experimental groups. FR decreased body weight (BW) with no effect on tail-cuff systolic blood pressure or in vivo heart rate (Table 1).

The echocardiographic study (Table 1) showed that FR did not change LVDD, increased LVSD, and reduced LVWT. Normalization of LVDD to BW showed that FR increased this ratio. Undernutrition decreased the LVWT/LVDD ratio and LV systolic performance assessed by the fractional shortening index.

The in vitro study (Table 2 ) showed that FR reduced $\mathrm{LVW}$ in proportion to $\mathrm{BW}$ reduction. The volume at zero $\mathrm{mmHg} \mathrm{LV}$ diastolic pressure (V0) was not changed after FR. Undernutrition reduced both the LVW/ V0 and LVWT/LVDD ratios, indicating the occurrence of eccentric ventricular remodeling (Figure 1). FR did not change $+\mathrm{dP} / \mathrm{dt}, \mathrm{P}_{\text {iso }}$ 0 and $\mathrm{P}_{\text {iso }} 25$ (Table 3). Food-restricted animals showed increased developed stress in both diastolic pressures (zero and $25 \mathrm{mmHg}$ ). $\mathrm{LV}$ relaxation, evaluated by the $-\mathrm{dP} / \mathrm{dt}$ index, was not affected by FR (Table 3). However, the $\varepsilon_{25}$ and $\Delta \mathrm{V}_{25}$ values respectively showed that FR reduced myocardial elasticity and LV compliance (Figure 2).

\section{Discussion}

The undernutrition protocol used in this experiment was based on the fact that human food deprivation is generally the result of a deficiency of all diet components (16). Investigators have been using different reduction levels of total chow amount without specific deficiencies (6,17-19). Our undernutrition protocol was effective by causing a marked body weight reduction. This study did not include a control group, preventing conclusions about the impact of hypertension on cardiac remodeling in normotensive animals.

FR did not change tail-cuff systolic blood 
pressure, in agreement with data reported by Gradin and Persson in a study on SHR (17). However, Overton et al. (20) found a reduction in blood pressure which was explained by diminished sympathetic support. As was also the case in the present study, these investigators did not observe FR interference with heart rate. Since we found no changes in tail-cuff systolic blood pressure or heart rate, we may assume that these parameters had no influence on the in vivo results.

FR did not alter LVDD but decreased LVWT; consequently, the LVWT/LVDD ratio was decreased in FR rats. In undernourished children and patients with anorexia nervosa, echocardiographic studies have always shown lower LVDD and LVWT $(1,2,21,22)$. In our laboratory, LVDD and LVWT reduction was seen in normotensive rats submitted to the same FR protocol. This highlights the question concerning the influence of hypertension on ventricular cavity remodeling in rats submitted to FR. The absence of a reduction in LV chamber size suggests an inability to adapt to hemodynamic load when undernutrition restricts myocardial growth. This was confirmed by the decrease in ejection index found in the in vivo study. The lower LVWT/LVDD ratio indicates that FR caused a change in the shape of the ventricular cavity, showing an eccentric remodeling.

The in vitro study confirmed the structural findings obtained in vivo; FR did not alter V0, but decreased LVW. Consequently, the LVW/V0 ratio was lower in FR rats, indicating eccentric remodeling.

FR decreased the ability of the LV to eject, which may have been caused by the reduction in myocardial contractility and/or cardiac load changes. The M-mode echocardiogram is an efficient method for in vivo studies, which, however, can be used only in the study of myocardial contractility. The study of the isolated heart from the same animal allowed us to gain a better under- standing of the in vivo changes. We did not observe changes in $+\mathrm{dP} / \mathrm{dt}$ or $\mathrm{P}_{\text {iso }} 0$, and $\mathrm{P}_{\text {iso }}$ 25 values in FR rats, a fact that may be interpreted as the maintenance of myocardial contractility $(23,24)$ since cardiac load
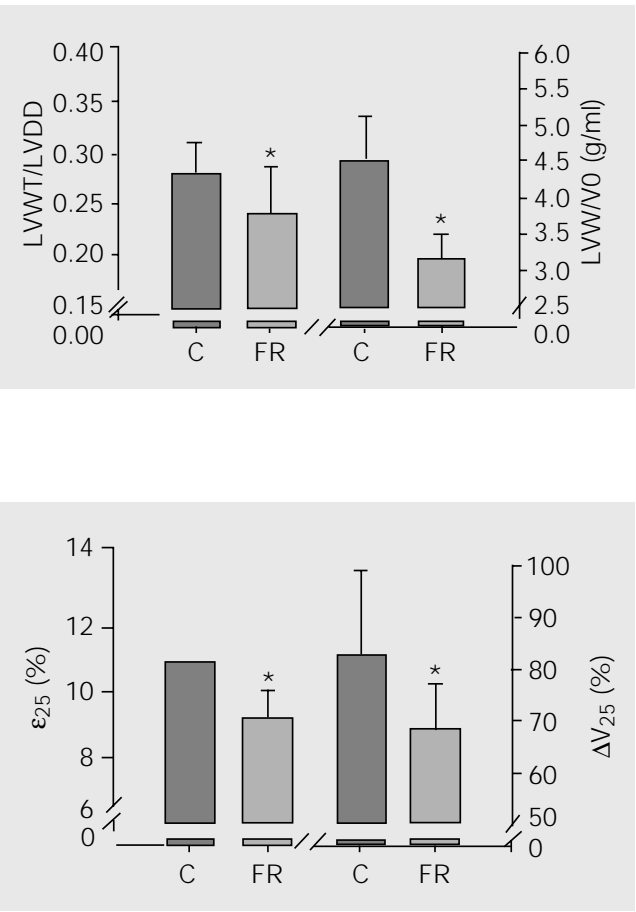

Table 3. Functional study of the left ventricle in an isolated Langendorff heart preparation.

\begin{tabular}{lcc}
\hline & Control & Food restriction \\
\hline Systole & & \\
$+\mathrm{dP} / \mathrm{dt}(\mathrm{mmHg} / \mathrm{s})$ & $3493 \pm 379$ & $3555 \pm 211$ \\
$\mathrm{P}_{\text {iso }} 0(\mathrm{mmHg})$ & $152 \pm 16$ & $149 \pm 15$ \\
$\mathrm{P}_{\text {iso }} 25(\mathrm{mmHg})$ & $155 \pm 9$ & $150 \pm 10$ \\
$\mathrm{DS}-0\left(\mathrm{~g} / \mathrm{cm}^{2}\right)$ & $104 \pm 19$ & $136 \pm 19^{*}$ \\
$\mathrm{DS}-25\left(\mathrm{~g} / \mathrm{cm}^{2}\right)$ & $174 \pm 19$ & $217 \pm 22^{*}$ \\
Diastole & & \\
$-\mathrm{dP} / \mathrm{dt}(\mathrm{mmHg} / \mathrm{s})$ & $2090 \pm 234$ & $1986 \pm 246$ \\
\hline
\end{tabular}

Data are reported as means \pm SD for 9 animals in each group. $+\mathrm{dP} / \mathrm{dt}=$ rate of rise of ventricular pressure; $\mathrm{P}_{\text {iso }} 0$ and $\mathrm{P}_{\text {iso }} 25=$ developed pressure at diastolic pressure of zero and $25 \mathrm{mmHg}$, respectively; DS-0 and DS- 25 = developed stress at diastolic pressure of zero and $25 \mathrm{mmHg}$, respectively; $-\mathrm{dP} / \mathrm{dt}=$ rate of decrease of left ventricular pressure.

$* P<0.05$ vs control (Student t-test).
Figure 1. Ratio of left ventricular wall thickness (LVWT) to diastolic diameter (LVDD) and ratio of left ventricular weight (LVW) to volume (V0). Data are reported as means \pm SD for 9 animals in each group. $\mathrm{C}=$ control group; $F R=$ food-restricted group. Note that both ordinates and abscissa are discontinuous. *P $<0.05$ compared to control animals (Student t-test).

Figure 2. Left ventricular diastolic function evaluated in the isolated heart. Data are reported as means \pm SD for 9 animals in each group. $\mathrm{C}=$ control group; $\mathrm{FR}=$ food-restricted group; $\varepsilon_{25}$ $=$ percentage of myocardial strain caused by a diastolic stress of $25 \mathrm{~g} / \mathrm{cm}^{2} ; \Delta V_{25}=$ percentage of variation in ventricular volume required to increase diastolic pressure from 0 to 25 $\mathrm{mmHg}$. Note that both ordinates and abscissa are discontinuous. $* \mathrm{P}<0.05$ compared to control animals (Student t-test). 
and heart rate were controlled in the study of the isolated isovolumetrically beating heart. We do not think that the increase of developed stress in FR rats is an indication of improved systolic performance because this index is inappropriate for the evaluation of myocardial contractility when the LV shows eccentric remodeling (7). However, an increased developed stress with unchanged systolic pressure may help understand the mechanism by which ventricular performance was impaired in the in vivo study on FR rats. Since both groups had the same in vivo arterial systolic pressure and undernutrition caused eccentric remodeling, we assumed that the FR rats presented a higher in vivo afterload. This increased afterload may explain the ventricular ejection impairment even when the inotropic state is unchanged. One might ask if the in vivo preload condition would favorably affect $\mathrm{LV}$ performance of FR rats, i.e., if for a given diastolic pressure the preload is higher in an eccentrically shaped ventricle. Consequently, preload reserve would be recruited in these hearts, helping systolic function. However, we believe that this was not the case in our study. We analyzed all hearts in the same diastolic pressure range, and systolic performance was the same in both groups.
FR caused a decrease in myocardial elasticity and ventricular compliance. In our previous studies, we observed that FR increased myocardial hydroxyproline concentration in adult and young normotensive rats $(3,7)$, possibly explaining the alterations found in the diastolic property. It was interesting to observe that the increase in myocardial stiffness and the consequent reduction in ventricular compliance occurred in the presence of eccentric remodeling. This remodeling, caused by a disproportional reduction in $\mathrm{LV}$ weight (or wall thickness) compared to LV volume (or diastolic diameter), might have led to increased ventricular compliance (25).

In summary, SHR submitted to FR for 90 days showed a reduction in $\mathrm{LV}$ wall thickness, eccentric remodeling, in vivo systolic performance depression, and changes in passive diastolic properties, with no changes in tail-cuff systolic blood pressure, heart rate, LV diastolic diameter, or myocardial contractility.

\section{Acknowledgments}

We thank J.C. Georgette, V.M. Souza, and M.A. Dallaqua for expert technical assistance and Colin E. Knaggs for revising the English text.

\section{References}

1. Simone G, Scalfi L \& Galderisi M (1994). Cardiac abnormalities in young women with anorexia nervosa. British Heart J ournal, 71: 278292.

2. St. J ohn Sutton MG, Plappert T, Crosby L, Douglas P, Mullen J \& Reichek N (1985). Effects of reduced left ventricular mass on chamber architecture, load, and function: a study of anorexia nervosa. Circulation, 72: 991-1000.

3. Cicogna AC, Padovani CR, Okoshi K, Matsubara LS, Aragon FF \& Okoshi MP (2001). The influence of temporal food restriction on the performance of isolated cardiac muscle. Nutrition Research, 21: 639-648.

4. Okoshi MP, Okoshi K, Dal Pai V, Dal Pai-Silva M, Matsubara LS \& Cicogna AC (2001). Mechanical, biochemical and morphological changes in the heart from chronic food restricted rats. Canadian J ournal of Physiology and Pharmacology, 79: 754-760.

5. McKnight KA, Rupp H, Dhalla KS, Beamish RE \& Dhalla NS (1999). Biphasic changes in heart performance with food restriction in rats.
J oumal of Applied Physiology, 87: 1909-1913.

6. Rossi MA \& Zucoloto S (1982). Ultrastructural changes in nutritional cardiomyopathy of protein-calorie malnourished rats. British J oumal of Experimental Pathology, 63: 242-253.

7. Fioretto J R, Queiroz SS, Padovani CR, Matsubara LS, Okoshi K \& Matsubara BB (2002). Ventricular remodeling and diastolic myocardial dysfunction in rats submitted to protein-calorie malnutrition. American J ournal of Physiology, 282: H1327-H1333.

8. Okoshi MP, Pai VD, Meyer MM, Pai-Silva MD \& Cicogna AC (1998). Morphological alterations in heart muscle tissue from undernourished hypertensive rats. J ournal of the American College of Cardiology, 31: 338C.

9. Yokota Y, Ota K, Ageta M, Ishida S, Toshima H \& Kimura N (1978). Effects of low protein diet on cardiac function and ultrastructure of spontaneously hypertensive rats loaded with sodium chloride. In: Kobayashi T, Ito Y \& Rona G (Editors), Recent Advances in Studies on Cardiac Structure and Metabolism. University Park Press, Balti- 
more, MD, USA.

10. Swoap SJ , Boddell P \& Baldwin KM (1995). Interaction of hypertension and caloric restriction on cardiac mass and isomyosin expression. American J oumal of Physiology, 268: R33-R39.

11. Katz AM (1994). The cardiomyopathy of overload: an unnatural growth response in the hypertrophied heart. Annals of Internal Medicine, 121: 363-371.

12. Pfeffer J M, Pfeffer MA \& Frohlich ED (1971). Validity of an indirect tail-cuff method for determining systolic arterial pressure in unanesthetized normotensive and spontaneously hypertensive rats. J ournal of Laboratory and Clinical Medicine, 78: 957-962.

13. Sahn DJ , DeMaria A, Kisslo J \& Weyman AE (1978). The Committee on M-Mode Standardization of the American Society of Echocardiography. Recommendations regarding quantitation in M-mode echocardiography: results of a survey of echocardiographic measurements. Circulation, 58: 1072-1083.

14. Doering CW, J alil J E, J anicki J S, Pick R, Shahriar A, Abrahams C \& Weber KT (1988). Collagen network remodeling and diastolic stiffness of the rat left ventricle with pressure overload hypertrophy. Cardiovascular Research, 22: 686-695.

15. J alil J E, Doering CW, Janicki J S, Pick R, Shroff SG \& Weber KT (1989). Fibrillar collagen and myocardial stiffness in the intact hypertrophied rat left ventricle. Circulation Research, 64: 1041-1050.

16. Hoffer LJ (1994). Starvation. In: Shils ME, Olson JA \& Shike M (Editors), Modern Nutrition in Health and Disease. Lea \& Febiger, Philadelphia, PA, USA.

17. Gradin K \& Persson B (1990). Blood pressure and sympathetic activity in spontaneously hypertensive rats during food restriction. J ournal of Neural Transmission, 79: 183-191.
18. Hilderman T, McKnight K, Dhalla KS, Rupp H \& Dhalla NS (1996). Effects of long-term dietary restriction on cardiovascular function and plasma catecholamines in the rat. Cardiovascular Drugs and Therapy, 10: 247-250.

19. Rupp H, Maisch B \& Brilla CG (1997). Schedule-induced psychological stress and molecular structures of cardiomyocytes. American J oumal of Physiology, 272: R776-R782.

20. Overton J M, VanNess J M \& Castro RM (1997). Food restriction reduces sympathetic support of blood pressure in spontaneously hypertensive rats. J ournal of Nutrition, 127: 655-660.

21. Bergman J W, Human DG, Moor MMA \& Schulz J M (1988). Effect of kwashiorkor on the cardiovascular system. Archives of Disease in Childhood, 63: 1359-1362.

22. Kothari SS, Patel TM, Shetalwad AN \& Patel TK (1992). Left ventricular mass and function in children with severe protein energy malnutrition. International J oumal of Cardiology, 35: 19-25.

23. Döring HJ \& Dehnert $\mathrm{H}$ (1988). The isolated perfused warm-blooded heart according to Langendorff. In: Döring $C$ (Editor), Methods in Experimental Physiology and Pharmacology. Biological Measurement Techniques. Biomesstechnik-Verlag, Berlin, Germany.

24. Little WC (2001). Assessment of normal and abnormal cardiac function. In: Braunwald E, Zipes DP \& Libby P (Editors), Heart Disease. A Textbook of Cardiovascular Medicine. W.B. Saunders Company, Philadelphia, PA, USA.

25. Gaasch WH (1994). Passive elastic properties of the left ventricle. In: Gaasch WH \& LeWinter MM (Editors), Left Ventricular Diastolic Dysfunction and Heart Failure. Lea \& Febiger, Philadelphia, PA, USA. 